\title{
SOBRE LAS ALTERACIONES DEL MIEDO EN ALGUNAS UTOPÍAS ACTUALES Y EN OTRAS NOVELAS RECIENTES
}

\section{ON THE ALTERATIONS OF FEAR IN SOME CONTEMPORARY UTOPIAS AND OTHER RECENT NOVELS}

\author{
Edgar Tello García ${ }^{1}$ \\ INS Pompeu Fabra Badalona
}

\author{
Recibido: 11/2/ 2016
}

Aceptado: 11/ 5/ 20168

Resumen: El trabajo trata de utilizar el sentimiento del miedo para hermanar algunas obras que utilizan la utopía, la distopía y la memoria del pasado. Ya se trate de paraísos o de mundos apocalípticos, el miedo es el elemento que sirve de transición para el retrato efectivo de estos lugares. Mostramos el final paradójico que espera a la utopía. Estudiamos esta idea a partir de los personajes que habitan diferentes utopías: la de Ishiguro en Nunca me abandones, y la de P. Heller en La constelación del Perro, entre otras. En segundo lugar pretendemos extender la sombra de la utopía a otros textos no utópicos: El país del miedo de Isaac Rosa; J.J. Millás en Cerbero son las sombras y A. Cervera en Todo lejos. En estos casos, la espera de un significado es la distopía que aliena la ficción. Finalmente, tratamos de identificar al creador/padre de la ley y sugerimos la posibilidad de que el miedo sea recíproco, tal y como sucedería en la otredad mutua, pese a la posible disimetría en su percepción.

Palabras clave: utopia; distopía; memoria; miedo; Ishiguro; Millás; I. Rosa.

Abstract: This paper shows how fearfulness is a transversal ingredient in utopia,
dystopia, and the memories of the past. Whether fiction is devoted to show a(n) (im)
possible paradise outside reality or an apocalyptical punishment, fear is the stressing
path to follow in order to arrive to utopia's consummation. We show the paradoxical
end that waits for utopia. We study the law that guides some recent characters from
different utopias: Ishiguro's Never Let me Go and P. Heller's The Dog Stars, among
others. Secondly, we want to project the shadow of utopia through other non-uto-
pian novels: I. Rosa's El país del miedo ('The Land of Fear'); Millás' Cerbero son las
sombras ('Cerbero are the shadows') and A. Cervera's Todo lejos ('Everything away').
The instance of waiting for a signification is the dystopia that alienates fiction in
these cases. Finally we try to identify the creator/father of the law and to suggest the

1. (etello@xtec.cat), INS Pompeu Fabra. Badalona. 
possibility of reciprocity, though also dissymmetry, in absolute fear as a kind of otherness.

Key Words: utopia; dystopia; memory; fear; Ishiguro; I. Rosa.

A l'Enric Gonzàlvez

\section{Dejando rodar la piedra de la memoria}

La felicidad es un lugar que no existe: una utopía. Algunos textos de la ficción reciente imponen al lector una visión desalentadora del mundo, la cual va acosando sus expectativas de un final feliz, hasta situarlo en un estado depresivo, en el que el miedo acecha, como un doble recurrente, al contemplar las similitudes y las posibles transferencias, entre los diversos mundos posibles. Para comprender este trasvase continuado, la descripción de R. Chirbes (2007: 193) puede resultar útil, al identificar la libertad con un modo de vida ordenado y feliz que puede acercarse a la utopía, mientras el miedo acucia como una modificación sospechosa e inteligente del discurso establecido: "la libertad, aunque se te haga extraño, aunque no te lo creas, se acuesta temprano, y duerme sus ocho horas de un tirón. La libertad se conquista teniendo un trabajo que te gusta y que te permite vivir como a ti te gusta. La empresa que tenemos es tu garantía de libertad."

No obstante, tal y como afirma P. Vieira en su definición de utopía, ésta permanece continuamente "estigmatizada por la idea de imposibilidad y por el totalitarismo" (2010: 22) y la distancia que la lectura impone no permite obviar un cierto miedo ante un entramado rígidamente controlado que (todavía) no tiene lugar, pero que resulta más vívido para sus actantes que la narración que quedará plasmada en los libros de historia ${ }^{2}$

Si en Platón (Mumford 1922: 58) el supuesto alivio científico del mundo utópico queda relegado al descarte genético, también en los autores actuales comprobamos que "después del miedo lo que llega es el olvido", según menciona un personaje de A. Cervera (2014: 103). Se produciría un proceso inverso al del mito de Sísifo de Camus: apartado de la ventana racional de conocimiento del mundo, el lector sufriría ante sus ojos la nueva

2. Esta es la idea de Vieira. La definición de utopía de Kenneth Roemer (2010: 79) "an alternative reality that critiques theirs [readers' reality]" incluye un matiz de crisis y perturbación que anuncia la distopía: si ese universo posible es "significantly worse." Sea como sea, trataré demostrar que el miedo es un elemento transversal también en la eutopía. Vid. también Fátima Vieira (2010) para la definición del concepto. El miedo a lo intercambiable de los roles en la utopía está expresado en Bégout (2010: 36), donde se asegura que "sólo más extrema verdad posee el poder desrealizante de la ficción." Véase un comentario sobre este texto más abajo. Para la lectura de Sísifo que hago a continuación, Greene (2005: 21). Para la invención de las historias y las culturas, véase el trabajo de Assmann (2014).

Thémata. Revista de Filosofía №55 (2017) pp.: 13-26. 
realidad igualmente racional, aceptada y feliz en su limitación segura, al ser más simple o hallarse más a la vista, para así "borrar de la cabeza lo que no nos gusta" (Cervera ibídem). Ante el recuerdo utópico hallaría un tipo de lectura inmune a la herrumbre de los signos, en el acercamiento a la pobreza moral de un miedo que funcionaría a modo de palimpsesto, borrando lo pernicioso y reflejando la exposición maravillosa de las leyes con un punto de cinismo ${ }^{3}$. Al cabo, "los que pierden lo que hacen es buscar la manera de recuperar lo que perdieron" (Cervera 2014: 157). En cambio, si la utopía es la descripción detallada y sistemática de un mundo mejor, opuesto al propio, el exceso de bondad y belleza en la ficción, produce no sólo la devaluación del recuerdo sino su esperpentización terrorífica (Fortunati 2000: 637).

El miedo a alterarse, a no ser nunca más uno mismo, que acecha a los personajes de I. Rosa (2008), es el miedo a llegar a ser algo diferente, a dejar una marca que quiera decir algo, cuando se sabe que nada de lo que se diga tendrá un significado que no sea irónico, en un lugar que ha creado de la nada sus propias leyes y tiene como dictum el no revelarlas hasta la consunción de sí mismo, cuando ya nadie pueda quedar excluido ${ }^{4}$. El miedo acosa desde las diversas dimensiones de lo posible, forzando un desplazamiento semántico hacia una personalización del vacío. Es el miedo inexplicable a la hibridación neutral de todos los sistemas en una anulación controlada y recreada de los roles de sus habitantes. $\mathrm{O}$ dicho de otro modo, es la utopía el caldo de cultivo ideal en el que se practica, siguiendo diferentes estrategias, el imposible arte del olvido, según el cual uno acaba recordando lo que desea olvidar (Eco-Migiel 1988: 254).

El acoso del miedo puede mostrarse como algo ajeno, pues siempre está fuera, acechando como una ilusión o una perturbación que afecta momentáneamente la percepción de la realidad de algún personaje. El sentimiento inconsolable buscado en los textos de K. Ishiguro, imprime un sentimiento de irrealidad de manera sostenida a lo largo de toda su obra. Encontramos una forma de nostalgia y abatimiento por no lograr

3. En El país del miedo de Isaac Rosa, un padre y un hijo son acosados por un adolescente: la incapacidad del padre para no ser sometido, evitando la violencia como rasgo de progreso incuestionable, se conduce a los protagonistas al cuestionamiento de la necesidad ineludible de la violencia. Hago guiños a términos conocidos de la teoría literaria. "La herrumbre de los signos" remite al ensayo de Magris (2008) sobre von Hommansthal. El "pacto de ficción" es de Wayne Booth (1961).

4. Cf. Derrida (2008: 145). Delumeau (1978: 186) allega exclusión y evaluación y explica cómo la peligrosa utopía surge del miedo a no ser aprobado; así, los estudiantes sienten ese mismo miedo ante los exámenes, por lo que acaba triunfando el trabajo en grupo y la evaluación continua. Cuando utilizo en cursiva el adverbio realmente, lo utilizo en un sentido heideggeriano, para quien las cosas se revelan realmente a la conciencia sólo por medio de la frustración (Bauman, 2003: 9).

Thémata. Revista de Filosofía $\mathrm{N}^{\circ} 55$ (2017) pp.: 13-26. 
encontrar el camino o las estructuras conocidas de un mundo que se ha vuelto ajeno ${ }^{5}$. Como apunta Patteson (2008: 125), el miedo es soslayado a través de las palabras que llenan un vacío increíble, pese a que el silencio de los muertos entra en conflicto con el murmullo de los rostros ausentes que tratan de recrear su momentánea identidad. Se trata de una forma tranquila, en apariencia, del acoso, siendo los muertos los encargados de extender su mano de sombras sobre el presente en crisis. En estas utopías, no es extraño hallar personajes que malviven subsumidos al sentimiento de expropiación ante un inminente desalojo (de Hailsham, de los Cottages, en Nunca me abandones), donde se percibe la felicidad de vivir una situación sin otra resistencia que la sumisión extrema ante la ley que les obliga, al fin, a donar sus órganos: para eso han sido creados. Tampoco es fácil comprender ni juzgar a estos personajes que ocultan, muestran y sufren deslices en sus recuerdos hasta que todo acaba encajando como en un puzzle ad hoc. Aceptan sus destinos, con el paradójico conocimiento de no estar viviendo las vidas que desearían vivir, o siquiera tener en el horizonte ninguna posibilidad de mejora; mientras que las únicas sonrisas que provoca el amor están bajo vigilancia y deben ser de acuerdo a la ley. Un orden se respira sin llegar a ser evidente del todo, pero insufla a los personajes la necesidad de callar y vivir, de modo que fuese evitable cualquier forma de pensamiento severo. La utopía literaria no es en modo alguno una forma de terapia, pues si se trata de una herida que la escritura trata de sanar, esta costra protectora no logra detener la hemorragia, ni el dolor, bajo el clima de extrema amabilidad (Reitano 2007: 362). En el contexto contemporáneo, no es extraño que la utopía devenga una compañera en el campo semántico de la locura, o una declaración criticable, al estar cargada, además de los matices anunciados, de connotaciones teológicas o humanistas (Mumford 1922: 9, 103).

A lo sumo, podemos también denominarla como un apósito, formado por palabras, sobre el que otro autor, Juan José Millás (Cerbero son las sombras, 46$)$, ha construido su espacio para proyectar sus sombras, pues

5. Hochmuth (2003) comprende que el acoso engendra una servidumbre que restringe la personalidad, y pretendo extender esta idea a la utopía. He explicado el sentimiento inconsolable en otro trabajo (Tello 2011); cuando menciono los "deslices", en la creación de los mundos de Ishiguro, me refiero olvidos momentáneos, según los define Schacter (2002: 33), "incomplete rather than total forgetting that leaves in its wake scattered shards of experience. Vague impressions of familiarity, general knowledge of what happened, or fragmentary details of experiences." En las conversaciones de Shaffer (2008: 91), más concretamente, se habla de la ocultación y mostración del pasado de los personajes de Ishiguro. Puede observarse la constelación acoso/miedo/inconsolable en uno de los textos recientes de Paul Auster (2010: 133): "Todo el mundo habla en voz baja, como si el alzarla por encima de un murmullo fuera una ofensa, un insulto contra el silencio de los muertos, y cuando observa los rostros a su alrededor, todos parecen estupefactos, agotados, un tanto ausentes, destrozados."

Thémata. Revista de Filosofía №55 (2017) pp.: 13-26. 
en la "relación existente entre tu herida y el resto de las cosas" el narrador ocupa el espacio del escriba que transcribe la ley, mientras que los delincuentes y los dementes la corroboran al transgredirla desde sus diversos papeles. El hecho de no poder actuar moralmente en estos mundos es irrelevante, pues se crea una ansiedad diferente en el miedo producido por la comprensión de que el refugio es inseguro, de que algún día habrá que salir de debajo de la cama (en el caso de Jacinto, en Cerbero son las sombras) y unirse, enfrentándose con los transgresores. El encuentro y la armonía nunca serán posibles fuera de la utopía, que los estudiosos no dejan de relacionar con la Ley Divina en la que se funde el gran Otro (Fox 1989; Rahema 1998).

\section{Esperando la alteración del sentido}

El sentido de un final modifica de forma fantástica la refracción de la herida sobre sí misma, e incluso produce, por medio de la utopía, un tipo de escritura impúdica que cobra una voz poco mesurada, nerviosa. La necesidad de actuar genera un estrés que planta al acosado ante el dilema de convertirse en verdugo ${ }^{6}$. En El país del miedo, I. Rosa (2008: 158) lo advierte en uno de los momentos centrales: "Siente que en el reparto de papeles en un combate uno suele ser espectador, alguna vez le tocará ser la víctima, pero tampoco puede descartar que un día le corresponda ser verdugo". También C. Fallarás, en Últimos días en el Puesto del Este (2012: 28), reafirma esta idea ante el escenario de defensa frente a un Apocalipsis reproducido una vez más que ha perdido toda aura divina: "la violencia es imprescindible. Todo es violencia”. Como afirma Lacan a propósito del crimen una sociedad queda cifrada por una ley teórica que el criminal se salta, por lo que esta teoría debe reescribirse (2006: 122). Lo peor del miedo es que se espera, ha sido un proceso paulatino de asimilación de una referencialidad diferente: "algo debe de haber sedimentado en tu interior. Algo debes de haber retenido inconscientemente, porque cuando llega un

6. Cf. Marina (2006: 38), para la relación entre miedo y estrés, un concepto comodín, como advierte el autor citado. "Un sujeto experimenta estrés cuando la presencia de acontecimientos que exigen de él un esfuerzo que sobrepasa sus recursos mentales o físicos le provoca un sentimiento desagradable, inquieto, debilitador, con signos de activación fisiológica." En la reciente Barcelona no existeix (2014: 24) de David Castillo encontramos un ejemplo de esta crítica a una sociedad esperpéntica que intersecta con la realidad política: "la paciència no era el meu fort. No en tens quan l'esperança ha desaparegut i l'unica possibilitat de ser tu mateix passa per ser anònim, sense particularitats."

Thémata. Revista de Filosofía $\mathrm{N}^{\circ} 55$ (2017) pp.: 13-26. 
momento como el que he descrito ya hay una parte de ti que ha estado esperando," nos dice Ishiguro en Nunca me abandones (2005: 54).

Desgraciadamente, lo que está por venir nunca llegará. Desde un punto de vista filosófico, los personajes que esperan, esperan el instante eterno por venir. No es extraño que ello genere angustia, pero sí que lo es que esta angustia se genere, al contrario, al modo de una revelación. El ser no existe mientras está viviendo en la matriz de significados construida por su civilización utópica. La muerte viene con su salida a lo abierto, con la revelación del sentido de la Ley ${ }^{7}$. Los protagonistas esperan que la felicidad extrema se perpetúe pero no son estúpidos y saben que en un momento u otro algo revelará su fallo: "hay gente ahí fuera, como Madame, que no te odia ni te desea ningún mal, pero que se estremece ante el mero pensamiento de tu persona [...] y que sienten miedo ante la idea de que tu mano pueda rozar la suya" (Ishiguro 2005: 54). El miedo es un reflejo tan inexacto como monstruoso de la personalidad. Al retratarlo como una mirada ajena, la alteridad conlleva una comprensión negativa de la identidad del otro. Una identificación que hace daño porque muestra las diferencias que el sujeto no puede ver y que lo alejan de sí mismo. Cuando surgen los fantasmas que el espejo no muestra parece imperar una ley del silencio general, donde la amenaza de que estos tomen la palabra se insinúa como la destrucción de la arquitectura en su presencia. La constatación de que la creación y la ilusión son parejas indisolubles puede asumirse por medio del diálogo; sin embargo todos los puentes han sido rotos, en este género estilizado, y el diálogo no es más que la constatación de una lucha tan inútil, cuanto sospechosa, en la utilización de la utopía como herramienta de análisis historiográfica (Roemer 2010: 81). Así, una realidad más honda aparece entre las ruinas del pasado suplantando el presente en colisión consigo mismo ${ }^{8}$. En El país del miedo, el agresor no reconoce en los protagonistas sino la posibilidad de que reconozcan su verdadero rostro; la violencia y la agresividad se reflejan en la mirada del agresor que les devuelve el "añadido" especular. Si el miedo es un lugar imaginado por el sujeto, con sus condiciones específicas, en el que habitan aquellos que lo sufren, (un centro de cuidados como Hailsham, para Ishiguro; o un apartamento recurrente y desdoblado como en los textos de Millás), la proyección de sus coordenadas no puede ser sino la racionalización de un lugar común que se ha vuelto ominoso. El sentido que señala sobre sí mismo es la imagen del gran ombligo de Ubu rey, donde la sobrecarga de significados produce lo

7. Sobre Bégout (2010: 35). Para la pedagogía griega remito a W. Jaeger (1947). Cf. Derrida (1994: 73), en quien inspiro estas líneas: "El tiempo está así compuesto de no-seres. Ahora bien, lo que comporta una cierta nada, lo que se acomoda con la no-entidad no puede participar de la presencia."

8. Vid. A. Penedo Picos (2001).

Thémata. Revista de Filosofía ํ55 (2017) pp.: 13-26. 
que Baudrillard diagnosticaría como "metástasis cancerosa" 9 . No es extraño, pues, que los habitantes de la utopía de Ishiguro se dediquen a donar sus órganos para proporcionar los reemplazos.

Lo que seduce de la utopía es la ambigüedad bidireccional con la que satura sus creaciones. Por un lado tenemos la sátira de un mundo eugenésicamente mejorado; por el otro se nos anuncia un lugar (Hailsham o el país del miedo), en el que los protagonistas se encuentran tan lejos de cualquier realidad y de la crítica que sobre esta pudieran imponer que el lector no puede sentir nostalgia por regresar al triste mundo de fuera. Los personajes, en su apatía crítica, se encuentran más lejos del espejo mimético que de cualquiera de los espacios que habitan. La pregunta a la que nos enfrentamos es la de si ese futuro "mejorado" no ha llegado ya. Si el realismo recreado e inventado no es sino una de las refracciones del silencio masivo ante los periodos de crisis. No es extraño que el miedo surja al observar los dobles alterados que caminan al lado de los lectores que meditan sobre el nuevo estado posible de las cosas: alteridad y utopía, en resumen, pero una alteridad en estado puro, surgida al leer los textos. El doble del lector, pasivo y silencioso habitante de un mundo ya creado, no tiene más remedio que aceptar la idea de que no ha participado en la creación aunque forme parte de ella: tiene que sufrir las habituales desgracias que afectan a sus habitantes (la esterilidad, la mistificación de cualquier emoción en Nunca me abandones; la imposibilidad de la violencia como único medio de acción en El país del miedo), obligándole a interrogarse por los límites de la ficción y del divertimento que esta parecía apuntar (Claeys 2010: 122). La ley impera firmemente para sostener la utopía, pero esta ley es incapaz de considerar los más elementales principios emocionales de sus ciudadanos. Al observar esta máxima, los límites de la "zona gris" de reglas y significados se vuelve innecesaria y no cabe esperar más que un nuevo dios ex machina que obligue a los habitantes de la ficción a deglutir pacientemente su icónico vellocino de oro, y la construcción de esta cultura positiva demuestra estar realmente articulada sobre "ficciones del caos." Vemos concomitancias con la concepción de cultura que posee este investigador, como "medio de pertenencia a una humanidad superior" (Assmann

\footnotetext{
9. Baudrillard 1983: 25: "obesidad de los sistemas de memoria, de los stocks de información que ya han dejado de ser manejables -obesidad, saturación de un sistema de destrucción que en estos momentos ya está superando sus propios fines, excrecente, hipertélico. La transpolítica también es eso: el paso del crecimiento a la excrecencia, de la finalidad a la hipertelia, de los equilibrios orgánicos a las metástasis cancerosas." Debo esta cita al profesor E. Gonzálvez. Vid. D. Suvin (2003) para las relaciones distópicas de la otredad en la utopía y los límites con la ciencia ficción. Cf. Vieira (2010: 11) para las reflexiones sobre ley y utopía: "utopias were still based on the idea that only law would ensure social order, thus conveying a negative vision of man." El matiz de pesimismo que ésta cobra está estudiado en los trabajos clásicos de Walsh (1962) y Hillegas (1967).
}

Thémata. Revista de Filosofía $\mathrm{N}^{\circ} 55$ (2017) pp.: 13-26. 
2011: 127 y 139). La utopía es el reverso aumentado de esta pretendida cultura que esconde el caos. En el caso de las distopías, la crueldad objetiva del narrador, como líder que manipula a sus seres creados, se expresa abiertamente, algo que puede observarse en un bello fragmento del libro de P. Heller, La constelación del perro (2014: 144):

La ola de conmoción que estremeció a pequeño grupo fue casi visible. El último en morir aquí había sido Ben, un niño de ocho o nueve años que se emocionaba mucho, más que cualquier otro, cada vez que me veía aterrizar y dejar a Jasper en el suelo. Muchas veces olvidaba las reglas y cruzaba la zona entre saltos y gritos de alegría con los brazos estirados hacia el perro, que se levantaba sobre sus cuartos traseros y meneaba la cola, y él, como las figuras de la urna griega, nunca llegaba a tocarlo.

En la utopía asusta la naturalidad de la aceptación, en la que todo está contado con la normalidad de quien se ha habituado a un sistema ajeno, ya sea outópico o eutópico. Ninguno de los personajes se sorprende en exceso de las reglas que rigen el sistema porque la adaptación es contagiosa. Contar y analizar el mundo creado nunca puede ser terapéutico, porque lo ominoso surge en la confluencia entre el universo retratado y el universo de lo posible que favorecen los logros del realismo ${ }^{10}$. A pesar de que los utopistas pretendan analizar, en primera instancia, aquello que vuelve "el mundo tolerable [...] la caída en una sima de desilusión nos ha servido de estímulo para debatir de forma más rigurosa" sobre el verdadero germen de la utopía (platónica) que no es otro que el de conocer si alguna justicia permitiría erradicar las diversas pobrezas y miserias (Mumford 1922: 23, 53). Sin este interrogante, el miedo no surge en el interior sino en la admiración y la sorpresa buscadas en el proceso de lectura: una de los mayores incomodidades se produce al conocer los límites y la necesidad de insertarse en ellos para aceptar la paradoja de que el miedo a la delimitación es el que deshace el poder déréalisant de la ficción. Tal y como muestra la historia de Le ParK (Bégout 2010: 22, 36), la mostración fundamental de la utopía precisa ir ligada a un control absoluto, panóptico, que puede extenderse a una generación de normas para la correcta interpretación de sus creaciones. El resistirse, o el tratar de comparar el conocimiento del mundo con la ley imperante, conlleva el descubrimiento de que los papeles entre los personajes y los lectores son intercambiables, pues todos están sometidos a una ley idéntica, si quieren entrar en la rela-

10. Cf. Ishiguro (2005: 184), para el miedo a "lo posible", el doble original que vive más allá de Hailsham y los Cottages y (2005: 164) para el desdoblamiento de las dos personalidades de Ruth que habían permanecido separadas.

Thémata. Revista de Filosofía ํ55 (2017) pp.: 13-26. 
ción de significados a la nunca acaban de acceder por completo, por mucho que se finja su simplicidad.

\section{El miedo (ir)reversible al Creador}

El miedo surge al comprobar la reversibilidad de los roles, por lo que dicha especularidad se extiende a la libertad de la autonomía individual en otros ámbitos ${ }^{11}$. El recuperar el sentido del conocimiento para esta libertad, y por tanto, recuperar el poder necesario para crear una nueva ley y ejercer una nueva autoridad nos habla también de esta simbolización refractante e infinita. Se trata, en el fondo, del miedo ancestral de no escapar todavía a la idea de que es el conocimiento el que ha creado el enrarecimiento del mundo creado, los recelos frankenstenianos y las catástrofes históricas. En mi opinión, leer la utopía sin su aura maligna, obvia la concepción moralista que funciona como un bálsamo contra los espejismos de estos mundos felices. Para distinguir la utopía de cualquier otro operador temático de la literatura sería necesario incluir el miedo como el microclima transversal de estas ficciones, debido a este abandono hacia el destino que acaba afectando, desde el espacio, a los personajes y al proceso de lectura ${ }^{12}$. Sorprende ahora el miedo radical que pone en duda la misma identidad del sujeto, que no ve un reflejo realista de sí mismo en esa ficción, pero tampoco deja de verlo pese a su percepción alterada. Se trasciende así el aspecto de puro divertimento, al reconocer los inconvenientes del caos en las alternativas que la seguridad del orden produce. La alienación de la utopía provocaría la delación de su distopía, por lo que no aparece de una manera explícita, proceso que minaría los meandros de la lectura implícita ${ }^{13}$. Al permanecer en silencio, en medio de una extraña belleza artística, la utopía revela la seriedad de la Illusionstörung. Vuelve a ser P. Heller el que nos proporciona una buena ejemplificación de este momento (2014: 227): "Iba a eclosionar una nueva era: la música desen-

11. Cf. Alonso-Fernández Rodríguez 2013. Sobre la destrucción del ideal de autonomía individual, v. Claeys (2010: 122).

12. No puedo detenerme en este proceso de lectura, pero Ishiguro (2005) sí que propone una interpretación dentro de su mundo de ficción, como si las leyes especiales de Hailsham incluyeran algunas alteraciones propias para la consideración de esa realidad interna. Por ejemplo (2005: 277): "miraba por la ventana y todo lo que alcanzaba mi vista estaba inundado. Era como un lago gigante, y veía desperdicios flotando bajo la ventana, tetrabriks vacíos, todo tipo de cosas. Pero no tenía ninguna sensación de pánico, ni nada parecido. Todo era bonito y estaba tranquilo."

13. Un ejemplo del miedo que ironiza la creación verbal lo encontramos en Le Clézio (1963: 95): "para mí, la tierra se ha metamorfoseado en una especie de caos, tengo miedo de los dinoterios, de los pitecántropos, del hombre de Neanderthal."

Thémata. Revista de Filosofía $\mathrm{N}^{\circ} 55$ (2017) pp.: 13-26. 
frenada, el hula-hoop, las chicas surfistas, Elvis. Desde la distancia todo aquello parecía una desquiciada compensación... ¿de qué? Del Gran Miedo que acechaba. Por primera vez en la historia de la humanidad, quizá desde el Arca, todos intuían el Fin." Podemos observar de nuevo las concomitancias apuntadas arriba entre la religión mesiánica y la ficción utópica.

Si hablamos del "sentimiento del miedo", pues, antes que de una emoción (siguiendo la distinción de Damasio 2003: 29), Millás demuestra, en Cerbero son las sombras, que la aprehensión de cada uno de los resortes emocionales que anuncian este estado, funciona como un virus que se transmite a través de la mirada, y la experiencia. El cebo que hace caer en la trampa del espacio creado comienza a erigirse en una relación casi religiosa, buberiana, entre el yo y el tú nombrados en la ficción, frente a los cuales queda un remanente llamado el ahí fuera: "en los sótanos de mi dolor se alumbraba la seguridad de que yo era también portador de los síntomas del miedo, que tú venías sintiendo por los hombres" (Millás 1975: 34). Lo que el autor nos descubre de manera fundamental es que la aparición del miedo en la utopía revela el artificio de su construcción; como una estrategia auto-referencial que desvela el espejismo del sueño, rompiendo el "mundo remoto y sin duda inexistente" (35) en el que es posible alejarse del dolor revelado por el miedo. Estos espacios tienen tan bien delimitados sus estratos como cualquier universo en el que las relaciones de poder sean tan vertebradoras como en el nuestro. En este sentido, como apunta Mainer (2009: 37) a propósito de Cerbero son las sombras, el miedo es el alimento y el producto de la sumisión a un mundo que no existe y que resulta un reflejo desequilibrado del modelo, en su recurrencia incesante. Así, las evidencias continuas acaban amplificando el poso de un sentimiento que ya existía.

No hay controversia respecto a la medula del miedo en la utopía: son los controladores del sistema, los grandes Hacedores y sus deshumanizados esbirros los que causan el terror, y de paso ayudan a formalizar los aspectos eutópicos (gracias a la seguridad y el orden que proporcionan a aquellos que, sin rostro, como masa, han sido asimilados al sistema). La personalización literaria de este Sumo Creador es el padre, aunque este cobre diversas caras en las ficciones que aquí relatamos (la Madame en Nunca me abandones, por ejemplo, que es la encargada de otorgar algo más de vida a los donantes, si estos demuestran estar enamorados). Desde la "Carta al padre" de Kafka, la diseminación de los errores del poder han abarcado una constelación tan enorme que es difícil delimitarla. Recuérdese que, en esa carta nunca enviada, Kafka acusa en las primeras líneas a su padre, de utilizar un método de enseñanza oblicuo con él, una ironía que a su hijo le resulta despiadada y contraproducente (Kafka, 2008: 17-18). Si entendida también en su vertiente all-pervading, la ironía es uno de los rasgos de la modernidad literaria, es prácticamente imposible escapar artísticamente a su influencia. No es 
extraño, pues, que el narrador de Cerbero son las sombras se felicite por la ausencia de palabras de su padre, cuando este está ya muy enfermo, por lo que Jacinto, "el otro" de la novela, "se sentiría bien, sin darse cuenta de que ya nunca más tendría miedo" (Millás, 1975: 87).

Lo grotesco del anuncio del miedo en la utopía es su dispersión, como apuntamos, al invadir todos los ámbitos del espacio creado, desde el mismo instante en que se enuncia. El padre de Kafka, el lector ideal de la misiva, los lectores de las utopías, y el padre del narrador de Cerbero son las sombras, pueden sentir un miedo equiparable al que sintieron los donantes de Hailsham, o el chico acosado de El país del miedo, puesto que la incomprensión y la otredad, si no es exactamente recíproca en las emociones producidas, sí que posee un sentimiento de reversibilidad en el sentimiento, en contra de su origen. Es sobre este miedo de doble sentido incontrolable, y por tanto consolador, sobre el que pivota la estructura arquitectónica de la utopía. Como explica Delumeau, en su ensayo sobre $E l$ miedo en Occidente, los mayores miedos en Occidente se produjeron a raíz del deseo de que se "enseñase a aprender," por lo que el desaprendizaje implícito desemboca en un malestar sedicioso, a la hora de enfrentarse directamente al discurso del padre. La ilusión del mundo plasmada en la construcción de la utopía engendra el miedo. La estructura de acogida, protectora, proporcionada por la utopía se enfrenta a lo abierto, por lo que el porvenir crea una angustia que se extiende al extremo ${ }^{14}$.

En el ápice radical, lo que hace el miedo es paralizar, impedir el habla en casos extremos, como defensa de la energía del ser en su silencio, aunque prepare el espacio vacío hacia la preocupación esencial que es la de restituir un concepto elevado de lo humano, en contra de la barbarie. En su silencio obligado, el miedo preserva un discurso no dicho, o una historia posible que es el reverso de toda utopía: por debajo de su construcción increíble, lo pensado es una metáfora de una apertura hacia lo ajeno, en la que el hombre y la mujer pueden estar más cerca de alguna forma de verdad, entendida ésta como libertad, esencia, duda. Si el trabajo comenzaba con la alusión a un texto de Chirbes, en el que la estilización de la realidad podía dar lugar a una utopía en la que el miedo indirecto paralizaba la comprensión recta del pasaje, también puede éste tener su reverso positivo y fomentar "el duro desaprendizaje de la realidad que le descubre que lo normal es sólo una cuestión de discutible consenso" (Ródenas 2009: 282). Si la realidad no es lógica, la pretensión de incluir la vida en un código

14. V. Delumeau 186. Como escribe el investigador más adelante (1978: 200): "el vacío de poder es un fenómeno ambiguo. Deja libre paso a fuerzas que permanecían comprimidas mientras la autoridad era sólida. Abre un período de permisividad. Desemboca en la esperanza, la libertad, la licencia y la fiesta. No segrega, pues, solo el miedo. También libera su contrario. ¿Cómo negar, no obstante, la carga de inquietud que oculta?"

Thémata. Revista de Filosofía $\mathrm{N}^{\circ} 55$ (2017) pp.: 13-26. 
no consensuado conlleva el descubrimiento de la facilidad con la que se componen éticas falseables. Como se ha dicho, también la mentira fingida, el discurso infinito, la excrecencia sin sentido, es otra de las reacciones provocadas por el miedo. No es extraño que la discusión sea un terreno fértil para la vigilia de la palabra humanista.

Barcelona, febrero de 2016

\section{Bibliografía citada}

Alonso, L. E.; Fernández Rodríguez, C. (2013): Los discursos del presente. Un análisis de los imaginarios sociales contemporáneos, Madrid: Siglo XXI.

Assmann, J. (2011): Historia y mito en el mundo antiguo. Los orígenes de la cultura en Egipto, Israel y Grecia, Madrid: Gredos.

Assmann, J. (2014): Violencia y monoteísmo, Barcelona: Fragmenta.

Auster, P. (2010): Sunset Park. Benito Gómez Ibáñez (trad.). Barcelona: Compactos Anagrama.

Baudrillard, J. (1983): Las estrategias fatales, Barcelona: Anagrama. 2000.

Bauman, Z. (2003): Amor líquido. Mirta Rosenberg y Jaime Arrambide (trad.). México: FCE.

Bégout, B. (2010): Le ParK, Paris: Allia.

Booth, W. (1961): Retórica de la ficción, Madrid: Taurus. 1978.

Castillo, D. (2014): Barcelona no existeix, Barcelona: Empúries.

Cervera, A. (2014): Todo lejos, Barcelona: Piel de Zapa.

Chirbes, R. (2007): Crematorio, Barcelona: Anagrama (Compactos).

Claeys, G. (2010): "The Origins of Dystopia”, en Claeys (ed.), Cam-

bridge Companion to Utopian Literature, UK: Cambridge UP, 107-31.

Damasio, A. (2003): Looking for Spinoza. Joy, Sorrow, and the Feeling Brain, USA: Harvest.

Delumeau, J. (1978): El miedo en Occidente. (Siglos XIV-XVIII. Una ciudad sitiada), Madrid: Taurus: 2012.

Derrida, J. (1994): "Ousia y Gramme", Márgenes de la filosofía. Trad. Carmen González. Madrid: Cátedra, 63-102.

Derrida, J. (2008): "How to Avoid Speaking: Denials", Psyche. Inventions of the Other. II, California: Stanford UP, 143-195.

Eco, U. - Migiel, M (1988): “An Ars Oblivonalis? Forget It!”, PMLA (103: 3). 254-61.

Fallarás, C. (2012): Últimos días en el Puesto del Este. Madrid: Segunda Edición.

Greene, B. (2005): The Fabric of the Cosmos. New York: Vintage Books. 
Heller, P. (2014): La constelación del perro. Rodríguez B.- Jiménez Buzzi M. (trad.). Barcelona: Blackie Books.

Hillegas, M. (1967): The Future as Nightmare: H.G. Wells and the Anti-Utopians. New York: Oxford UP.

Hochmuth, T. (2003): The Incompatibility of Self and Service as Presented in Kazuo Ishiguro's The Remains of the Day, Roskilde Univ: Denmark.

Fortunati, V. (2000): "Utopia as a Literary Genre", Dictionary of Literary Utopias. Paris: Honoré Champion. 634-43.

Fox, R. (1989): Gandhian Utopia: Experiments with Culture, Boston: Beacon Press.

Ishiguro, K. (2005): Nunca me abandones. Zulaika, J. (trad.). Barcelona: Compactos Anagrama, 2009.

Jaeger, W. (1947): Paideia. Los ideales de la cultura griega, México: FCE, 1990.

Kafka, F. (2008): Carta al padre, Buenos Aires: Gradifco.

Lacan, J. (2006): Écrits. Trad. Bruce Fink. New York: Norton \& Company.

Le Clézio, J.M.G. (1963): El atestado. Cantero, S (trad.). Madrid: Cátedra, 2008.

Magris, C. (2008): Carta de Lord Chandos de Hugo von Hofmannsthal. La herrumbre de los signos, Madrid: Alianza.

Mainer, J.C. (2009): "El orden patriarcal, el orden del mundo: motivos en la obra de Juan José Millás”, en Andrés-Suárez, I; Casas, A. (eds.). Juan José Millás. Madrid: Arco/Libros, 23-46.

Marina, J. A. (2006): Anatomía del miedo. Un tratado sobre la valentía, Barcelona: Anagrama.

Matthews, S.; Groes, S. (2009): Kazuo Ishiguro: Contemporary Critical Perspectives, London and New York: Continuum.

Millás, J.J. (1975): Cerbero son las sombras, Barcelona: Booket. 2011.

Mumford, L. (1922): Historia de las utopias. Sanromán, D.L. (trad.). Logroño: Pepitas de Calabaza. 2013.

Patteson, R. (2008): "The Teller's Tale: Text and Paratext in Auster's Oracle Night." Critique: Studies in Contemporary Fiction, 49, 2, 115-30.

Penedo Picos, A. (2001): "El presente como arquitectura del sujeto." DC Papers. Revista de crítica i teoria de l'arquitectura. 5-6. 125-133.

Rahema, A. (1998): An Islamic Utopian: A Political Biography of Ali Shari'ati, London: Tauris.

Reitano, N. (2007): "The Good Wound: Memory and Community in The Unconsoled",Texas Studies in Literature and Language, 49, 4, 361-386.

Ródenas de MOYA, D. (2009): "La epistemología de la extrañeza en las columnas de J.J. Millás,” en Andrés-Suárez, I; Casas, A. (eds.). Juan José Millás. Madrid: Arco/Libros, 275-95.

Roemer, K. (2010): "Paradise Transformed: Varieties of Nine- 
teenth-Century Utopias", en Claeys (ed.), Cambridge Companion to Utopian Literature, UK: Cambridge UP, 79-106.

Rosa, I. (2008): El país del miedo. Barcelona: Seix Barral.

Schacter, D. (2002): The Seven Sins of Memory: How the Mind Forgets and Remembers, Boston/New York: Houghton Mifflin Company.

Shaffer, B. (2008): Conversations with Kazuo Ishiguro, Jackson: Mississippi UP.

Suvin, D. (2003): “Theses on Dystopia 2001", Dark Horizons: Science Fiction and the Dystopian Imagination, New York: Routledge, 187-201.

Tello, E. (2011): "Después de la fotografía: sobre la naturaleza inconsolable en La noche de los tiempos de A. Muñoz Molina y Vértigo de W. G. Sebald”, Moenia, 16, 411-426.

Vieira, P. (2010): "The concept of utopia", en Claeys (ed.), Cambridge Companion to Utopian Literature, UK: Cambridge UP, 3-27.

Walsh, C. (1962): From Utopia to Nightmare, London: Geoffrey Bles. 